\title{
Análise espacial da relação entre qualidade da educação e especialização produtiva no estado do Paraná
}

\author{
Renata Cattelan ${ }^{1}$ \\ Fernanda Mendes Bezerra ${ }^{2}$ \\ Marcelo Lopes de Moraes $^{3}$
}

\begin{abstract}
Resumo: Os setores econômicos em geral sofrem modificações com a inserção de capital humano, alguns com mais intensidade do que outros. Por este motivo, a educação tem papel primordial no crescimento e no desenvolvimento de uma nação. Neste sentido, o objetivo desta pesquisa é verificar se existe relação espacial entre a qualidade do ensino e a especialização dos setores produtivos. Ainda, verificar em qual dos setores a influência da educação é mais significativa. A metodologia utilizada foi a Análise Exploratória de Dados Espaciais (AEDE) com objetivo de identificar espacialmente como ocorre a associação entre as duas variáveis para os municípios do estado do Paraná, para os anos de 2012 e 2016, comparativamente. A variável utilizada para medir a qualidade do ensino foi o IDEB, enquanto que a variável referente à especialização dos setores foi calculada por meio do Quociente Locacional (QL), utilizando como variável base o número de empregos por setor. Os principais resultados indicaram que a especialização do setor agropecuário e do setor de serviços é associada negativamente com a variável IDEB, enquanto que os setores do comércio, construção civil e indústria apresentam relação positiva com a qualidade da educação, para os dois anos.
\end{abstract}

Palavras-Chave: Análise Exploratória de Dados Espaciais. Educação. Setores produtivos.

Abstract: The economic sectors in general are modified by the insertion of human capital, some with more intensity than others. For this reason, the education plays a major role in the growth and development of a nation. In this sense, the objective of this research is to verify if there is a spatial relationship between the quality of education and the specialization of the productive sectors. Also, to verify in which of the sectors the influence of education is more significant. The methodology used was the Exploratory Analysis of Spatial Data (AEDE) with the objective of identifying spatially how the association between the two variables occurs for the municipalities of the state of Paraná, for the years of 2012 and 2016, comparatively. The variable used to measure the quality of teaching was the IDEB, while the variable referring to the specialization of the sectors was calculated using the Locational Quotient $(\mathrm{QL})$, using the number of jobs per sector as the base variable. The main results showed that the specialization of the agricultural sector and the services sector is negatively associated with the IDEB variable, while the trade, construction and industry sectors show a positive relationship with the quality of education for the two years.

Keywords: Education. Exploratory Analysis of Spatial Data. Productive sectors.

\footnotetext{
${ }^{1}$ Economista graduada e Mestre em Gestão e Desenvolvimento Regional pela Universidade Estadual do Oeste do Paraná (UNIOESTE)/Campus de Francisco Beltrão. E-mail: renata.cattelan@gmail.com.

${ }^{2}$ Economista graduada pela Universidade Estadual de Londrina. Doutora em Economia pela Universidade Federal de Pernambuco. Professora adjunta da Universidade Estadual do Oeste do Paraná (UNIOESTE)/Campus de Francisco Beltrão e do Programa de Pós-Graduação em Gestão e Desenvolvimento Regional (PGDR). E-mail: ferpompeia@gmail.com.

${ }^{3}$ Economista graduado pela Universidade Estadual de Maringá. Doutor em Economia pela Escola Superior e Agricultura Luiz de Queiroz da Universidade de São Paulo (USP). Professor adjunto da Universidade Estadual do Oeste do Paraná (UNIOESTE)/Campus de Francisco Beltrão e do Programa de Pós-Graduação em Gestão e Desenvolvimento Regional (PGDR). E-mail: marcelomoraes.unioeste@gmail.com.
} 


\section{Introdução}

A educação é um dos aspectos necessários para o desenvolvimento das nações e o tratamento dado a este fator depende de questões históricas, culturais, políticas, ideológicas, dentre outros aspectos. O capital humano tem peso significativo na evolução de países, e como capital humano entende-se não somente a educação formal, mas as experiências, as habilidades e atributos adquiridos no convívio social.

Autores como Theodore Schultz e Gary Stanley Becker, dentre outros, procuraram compreender a importância da educação, enquanto aprimoramento humano, para o crescimento econômico. Schultz (1973) propôs que o capital humano é um investimento e é primordial para o sucesso das organizações modernas. Becker (1994) procura evidenciar que o investimento em educação é o mais importante com relação às pessoas e que existem evidências de aumento nos rendimentos médios de pessoas com maiores formações.

No Brasil, ainda são identificados problemas com relação à qualidade da educação. Os dados da Pesquisa Nacional por Amostra de Domicílios (PNAD), entre 2007 e 2014, apontaram o aumento do nível médio de instrução dos indivíduos, segundo o Instituto Brasileiro de Geografia e Estatística (IBGE, 2018). Porém, Bassi, Codes e Araújo (2017) descrevem que o fator qualitativo ainda apresenta níveis insatisfatórios, e que o desenvolvimento tardio do Brasil contribuiu para a falta de estrutura no ensino.

Quanto à qualidade educacional, um dos principais indicadores no Brasil é o Índice de Desenvolvimento da Educação Básica (IDEB) 4 . A partir de dados do Censo Escolar e do Sistema de Avaliação da Educação Básica (SAEB), é feita uma relação entre os valores observados desse índice e as metas para os próximos anos. Para os anos iniciais do ensino fundamental na esfera pública, todas as metas foram atingidas (2007, 2009, 2011, 2013 e 2015). Já nas escolas privadas, apesar de obterem um índice acima do das escolas públicas, não atingiram suas metas para todos os anos. Essa mesma tendência acontece para os anos finais do ensino fundamental e para o ensino médio ${ }^{5}$ (INEP, 2017).

Os anos finais do ensino fundamental deixaram de atingir suas metas desde 2013 e compreendem índices menores que nos anos iniciais. Mesmo sem alcançar a meta, os anos finais do ensino fundamental têm aumentado as suas notas. Já no ensino médio há uma estagnação do índice nos últimos três anos (2011, 2013 e 2015), sendo que na esfera privada a nota decresceu nos últimos dois anos (2013 e 2015). Além disso, o índice do ensino médio é menor que os obtidos pelo ensino fundamental (INEP, 2017).

\footnotetext{
${ }^{4}$ O IDEB é um indicador que mede a qualidade do sistema de ensino básico no Brasil. O cálculo combina duas dimensões, o aprendizado, por meio de uma prova, e o fluxo escolar, por meio da distorção entre idade e série. A fórmula é $\mathrm{IDEB}=\mathrm{NxP}$, onde $\mathrm{N}$ é a nota da prova e $\mathrm{P}$ é o índice de aprovação, calculado como $1 / \mathrm{T}$, onde $\mathrm{T}$ é o tempo médio de permanência na série. É calculado no Brasil a cada dois anos (BASSI; CODES; ARAÚJO, 2017).

${ }^{5}$ Os anos iniciais do ensino fundamental são aqueles do ensino básico entre o primeiro e o quinto ano, os anos finais estão entre o sexto e o nono ano e o ensino médio corresponde aos três últimos anos do ensino básico (MEC, 2019).
} 
Tendo em vista essa relação de aumento da escolarização, no sentido quantitativo e estagnação da qualidade do ensino, no sentido qualitativo, e ainda, explorando a influência disso sobre os setores produtivos da economia, a problemática da presente pesquisa é: qual a relação entre a qualidade da educação e a especialização dos setores produtivos?

Deste modo, o objetivo deste estudo é verificar se existe relação espacial entre a qualidade do ensino, medida pelo IDEB, e a especialização dos setores produtivos, medida pelo Quociente Locacional (QL), nos municípios paranaenses, para os anos de 2012 e 2016.

Sabe-se que o acesso à educação de qualidade leva à redução das desigualdades sociais, aumenta o trabalho capacitado e ajuda a nação como um todo a se desenvolver com base em um trabalho mais produtivo. Por este motivo é importante compreender como a qualidade da educação tem afetado os setores econômicos.

Para atender a proposta desta pesquisa o trabalho divide-se, além desta introdução, em mais quatro seções. A seção seguinte aborda a Teoria do Capital Humano. Posteriormente é apresentada a metodologia utilizada e, na sequência, discutem-se os resultados obtidos na pesquisa. Por fim, tem-se as considerações finais.

\section{Teoria do Capital Humano}

A Teoria do Capital Humano desenvolvida por Theodore Schultz tornou-se uma base teórica que condiciona a importância da educação, na qualidade de aprimoramento humano, para o crescimento econômico. Schultz (1973) indica que os recursos humanos são essenciais no sucesso das organizações modernas. Defende que os recursos financeiros e outros tipos de capitais dependem da ação humana eficaz para que seja estável e cresça.

A centralidade da Teoria do Capital Humano busca mostrar que a educação é um investimento como em qualquer outro capital. Schultz (1961) procura, incialmente, construir um conceito de capital humano e passa a tomar o trabalho como uma forma de capital; desta maneira, as pessoas gastariam tempo e recursos investindo naquilo que teria um provável retorno nos rendimentos futuros do indivíduo.

Batistela (2013) compreende que, conforme é posta, a teoria de Schultz provoca uma educação, em âmbito nacional, formadora de força de trabalho. Assim como o investimento pessoal, o governo pensa na educação como uma forma de investimento para um crescimento que trará retorno financeiro ao país, o que colabora para o desenvolvimento.

Outros autores procuraram evidenciar que o investimento em educação influencia o crescimento de uma nação. Becker (1994) coloca que o investimento mais importante que se faz em pessoas é a educação. O autor discute ainda que há muitas evidências empíricas, ressaltadas por diversos 
estudos, de que os rendimentos médios de pessoas com formação mais elevada são maiores, embora isso seja mais evidente em países menos desenvolvidos.

Essa tendência de aumento de ganhos entre pessoas com maior tempo de escolarização remete ao todo do sistema econômico obtendo ganhos com o aumento da produtividade do trabalhador, assim como com seus conhecimentos sendo aplicados para melhorar o trabalho. $\mathrm{O}$ aumento da renda média da população resulta em aumento da renda nacional na qual se obtém um saldo positivo de melhoras em geral.

Becker (1994) elucida que o conhecimento adicional gerado pela formação do ensino médio ou da educação superior são intimamente importantes em uma economia que deseja crescer e que tenham avanços tecnológicos. O crescimento persistente obtido em alguns países como, por exemplo, os Tigres Asiáticos, vieram do investimento maciço em educação e formação. A expansão do conhecimento científico e técnico ajudou a melhorar a produtividade tanto do trabalho, como de outros insumos de produção.

Outros autores contemporâneos discutem sobre a influência da educação no desenvolvimento. Viana e Lima (2010) concordam em dizer que a educação torna as pessoas mais produtivas e que isso aumenta seus salários, o que influencia no progresso econômico. Contudo, esta análise precisa levar em consideração a qualidade da educação que se está empregando. Isso porque, para o pleno desenvolvimento de uma nação é necessário dinamizar a cadeia produtiva e isso só é possível com educação de qualidade.

Waltenberg (2006) se posiciona dizendo que alguns estudos apontam para o fato de que o rendimento escolar tem muito mais a ver com as condições socioeconômicas do aluno do que com os recursos injetados na educação. Isso permite visualizar que a qualidade da educação não depende tão somente dos recursos financeiros.

Pauli, Nakabashi e Sampaio (2012) fazem uma análise da escolaridade brasileira por setores produtivos entre os anos de 1990 e 2006. Indicam que no setor agropecuário a maior parcela dos trabalhadores era escolarizada até o $5^{\circ}$ ano do ensino fundamental. $\mathrm{O}$ setor da indústria mudou de perfil ao longo dos anos, chegando em 2006 com a maior parte da sua força de trabalho com o ensino médio completo, mesmo caso do setor de serviços.

\section{Metodologia}

Esta pesquisa tem caráter exploratório e quantitativo. As subseções que seguem apresentam o procedimento metodológico que, para esta pesquisa, será dividida em duas partes: QL e AEDE. 


\section{Quociente Locacional (QL)}

Conforme Haddad (1989), o QL é uma medida setorial que se preocupa com a localização das atividades entre as regiões, com intuito de identificar a concentração ou a dispersão espacial do emprego setorial. O QL é expresso pela fórmula:

$$
Q L_{i j}=\frac{\frac{E_{i j}}{E_{i o}}}{\frac{E_{o j}}{E_{o}}}
$$

onde: $E_{i j}=$ variável base do setor i da região j; $E_{i,}=$ somatório da variável base dos setores da região j; $E_{s j}=$ somatório da variável base dos setores i da economia nacional; $E_{\mathrm{a}}=$ somatório da variável base dos setores da economia nacional.

Esta medida de localização compara a participação percentual de uma região em um setor com a participação percentual da mesma região no total da variável base da economia considerada como o total (HADDAD, 1989).

Conforme Haddad (1989), quando o resultado do QL > 1 significa que o local é relativamente mais importante em termos de setor do que em termos gerais de todos os setores. Indica, assim, a especialização da região. Já quando o $\mathrm{QL}<1$, indica uma atividade que não é representativa no todo, ou seja, não especializada naquele setor.

Suzigan et al. (2003), indica que, apesar desse coeficiente ser amplamente utilizado, ele tem algumas limitações, como o fato de não ser adequado para estruturas produtivas mais diversificadas, por exemplo, as regiões metropolitanas, ou mesmo regiões muito pobres, onde uma única empresa, mesmo que pequena, pode revelar especialização. Indica-se, portanto, um aprofundamento dos resultados, procurando as causas da especialização em cada local.

\section{Análise Exploratória de Dados Espaciais (AEDE) ${ }^{6}$}

$\mathrm{Na}$ AEDE, o local onde ocorre um fenômeno é muito importante. Por este motivo, é possível verificar dois tipos de efeitos, um em que a dependência gera heterogeneidade espacial e outro em que a heterogeneidade gera a dependência espacial.

No efeito de dependência, o que se observa é a interdependência entre as regiões analisadas. Este efeito está fundamentado na Lei de Tobler, que afirma que tudo está interligado, mas o que está mais próximo gera maior dependência do que aquilo que está mais longe. São indicados quatro efeitos espaciais: difusão, troca de bens e serviços e transferência de renda, comportamento estratégico e espraiamento.

\footnotetext{
${ }^{6}$ Esta seção está baseada em Almeida (2012).
} 
A difusão compreende que pode ocorrer propagação espacial de certos atributos, algo relacionado ao efeito transbordamento. A troca de bens e serviços e/ ou a transferência de renda, consiste em efeitos de dispersão ou concentração que geram dependência entre os ambientes. O comportamento estratégico deriva da característica de influência entre as regiões, que pode ser de cooperação ou de competição. O espraiamento gera dependência ou similaridade por alguma característica disseminada pela própria população, comumente por meio da migração.

Para mensurar estes efeitos, utiliza-se a autocorrelação espacial, definida pela associação dos valores de determinada variável entre as regiões. Para determinar a ponderação de influência em um local, são definidos os vizinhos por meio de uma matriz de proximidade. A partir dessa matriz, é calculada a estatística I de Moran, que testa se há aleatoriedade dos dados. Isso quer dizer que se o coeficiente estatístico calculado demonstrar que não há aleatoriedade nos dados, a indicação de autocorrelação espacial se baseará no valor apresentado negativo ou positivo.

Se o coeficiente trouxer um valor positivo, há uma condição de similaridade, em que, locais com valor alto para a variável estará rodeado de outros locais também com valores altos (alto-alto), ou então, que locais com valores baixos da variável estarão rodeados por municípios que também apresentam valores baixos (baixo-baixo). De forma contrária, a dissimilaridade compreende os resultados negativos do coeficiente, em que, se pode observar o padrão de alto-baixo ou baixo-alto. Ou seja, locais que apresentam alto valor da variável estarão rodeados por locais com baixos valores ou vice-versa.

De forma matricial, o coeficiente I de Moran pode ser expresso como:

$$
I=\frac{W}{S_{0}} \frac{z^{\prime} W_{z}}{z \cdot z}
$$

onde: $\mathrm{z}=$ valores das variáveis padronizadas; $\mathrm{N}=$ número de regiões; $\mathrm{W}_{\mathrm{z}}=$ valores médios da variável padronizada nos vizinhos; $\mathrm{S}_{\mathrm{o}}=$ somatório de $\mathrm{w}_{\mathrm{ij}}$.

Para determinar a ponderação de influência, será utilizado neste estudo o critério chamado de queen, ou rainha ${ }^{7}$. Este formato leva em consideração todos os vizinhos que fazem fronteira com o município que está sendo observado.

No contexto deste estudo serão utilizadas duas variáveis, com objetivo de verificar a associação espacial entre elas. Por este motivo será empregada a autocorrelação espacial local bivariada, assim, que, seguindo a mesma lógica da univariada, procura demonstrar se uma variável em determinado local tem associação com outra variável nas localidades vizinhas. Para a estatística bivariada, o cálculo da estatística I de Moran precisa considerar as duas variáveis. Algebricamente, tem-se a equação:

$$
I^{z 1 z 2}=\frac{n}{s_{0}} \frac{z_{1} W z_{2}}{z_{1} z_{1}}
$$

\footnotetext{
${ }^{7}$ Há outros critérios que podem ser adotados, sendo que o mais adequado é aquele que apresenta a maior correlação. Para mais, consultar Almeida (2012).
} 
onde: $z_{1}$ e $z_{2}=$ representam as variáveis dependentes.

Embora haja alteração no cálculo da estatística, a interpretação permanece inalterada, sendo feita da mesma maneira que na interpretação univariada. Para o padrão da autocorrelação espacial local, é possível ainda capturar padrões pelo Local Indicator of Spatial Association (LISA), que indica clusters espaciais significativos estatisticamente e proporcionais ao indicador de autocorrelação global. Esses clusters são expressos pelos padrões alto-alto, baixo-baixo, alto-baixo e baixo-alto.

Para a elaboração deste estudo o softwware GEODA será utilizado para realização dos cálculos estatísticos.

\section{Procedimentos metodológicos}

O recorte geográfico utilizado é referente aos municípios do estado do Paraná, e o recorte temporal são os anos de 2012 e 2016, escolhidos tendo em vista o universo mais recente e a disponibilidade de dados.

As variáveis utilizadas nessa pesquisa foram: a) o IDEB dos anos de 2007 e 2011 para o ensino fundamental séries finais, com dados retirados do Instituto Paranaense de Desenvolvimento Econômico e Social (IPARDES, 2017); b) QL dos setores agropecuário, comércio, construção civil, indústria e serviços para os anos de 2012 e 2016, com valores calculados a partir de dados do número de empregos da Relação Anual de Informações Sociais (RAIS) (BRASIL, 2017b).

A variável IDEB foi selecionada por avaliar qualitativamente o sistema educacional. O IDEB ainda não é feito para o ensino médio em todas as escolas e não há um índice por município, por este motivo optou-se por utilizar o IDEB dos anos finais do ensino fundamental, anterior a entrada no ensino médio. O IDEB do ano de 2007 será utilizado comparativamente às demais variáveis do ano de 2012, isto porque pressupõe-se que os alunos que acabaram o ensino fundamental no ano de 2007 precisariam de pelo menos mais cinco anos para entrar no mercado de trabalho e passar a contribuir produtivamente com algum setor. Seriam mais três anos no ensino médio e mais dois anos de entrada no mercado de trabalho e adaptação. O mesmo ocorre para o IDEB do ano de 2011, que será utilizado comparativamente com as variáveis do ano de 2016.

Para aplicação da metodologia foram utilizados dados do número de empregos formais, como variável base, indicados pela Relação Anual de Informações Sociais (RAIS) por meio do site do Ministério do Trabalho e Emprego (MTE) para os anos de 2012 e 2016. Foram coletados dados de empregos por ano, por setor de atividade (agropecuário, comércio, construção civil, indústria e serviços) e por município do estado do Paraná (BRASIL, 2017b). 
Após a coleta das variáveis, calculou-se o QL para todos os municípios do Paraná e para os grandes setores produtivos: agropecuário, comércio, construção civil, indústria e serviços. O QL de cada setor por município e para cada ano será uma das variáveis de correlação utilizadas na AEDE.

A partir do QL, enquanto variável, foi possível fazer a AEDE correlacionando o QL de cada município para determinado setor com o IDEB dos municípios vizinhos.

\section{Apresentação dos resultados e discussão}

Nesta seção faz-se a apresentação dos resultados e discussão. Primeiramente, será feita uma análise descritiva das variáveis, a fim de contextualizar os dados e seus padrões. Posteriormente, serão apresentados os resultados no que concerne à AEDE.

\section{Análise descritiva dos dados}

Na Tabela 01 observa-se a estatística descritiva para as variáveis. A nota média do IDEB aumentou de 3,9 para 4,0, contudo, o valor mínimo de 2007 para 2011 caiu de 2,7 para 2,6 enquanto que o máximo aumento de 5,2 para 5,4. Isto fez com que o desvio-padrão também aumentasse, expressando que as diferenças entre as notas e a média ficaram maiores.

O número de empregos no setor agropecuário de 2012 para 2016 aumentou na média dos municípios paranaenses, sendo que o desvio padrão diminuiu, indicando uma menor dispersão dos dados em torno da média. Para o setor do comércio, a média de empregos aumentou de 2012 para 2016, e houve redução do desvio padrão. O setor da construção civil teve uma média menor no ano de 2016 em comparação com o ano de 2012 no número de empregos por município.

Tabela 01 - Estatística descritiva dos dados para a variável IDEB (2007 e 2011) e número de empregos por setor (2012 e 2016 )

\begin{tabular}{l|l|l|l|l}
\hline Variável & Mínimo & Máximo & Média & Desvio Padrão \\
\hline IDEB2007 & 2,7 & 5,2 & 3,950 & 0,443 \\
Agropec2012 & 0 & 3.283 & 257,251 & 435,249 \\
Comércio2012 & 0 & 160.778 & $1.620,043$ & $8.871,050$ \\
ConstCivil2012 & 0 & 52.961 & 379,509 & $2.814,477$ \\
Indústria2012 & 0 & 128.254 & $1.784,531$ & $7.380,302$ \\
Serviços2012 & 129 & 624.022 & $3.561,837$ & $31.812,085$ \\
\hline IDEB2011 & 2,6 & 5,4 & 4,082 & 0,466 \\
Agropec2016 & 2 & 3.367 & 260,837 & 420,312 \\
Comércio2016 & 1 & 152.361 & $1.649,915$ & $8.482,278$ \\
ConstCivil2016 & 0 & 39.820 & 308,331 & $2.134,629$ \\
Indústria2016 & 0 & 98.113 & $1.633,454$ & $5.910,830$ \\
Serviços2016 & 136 & 590.872 & $3.699,105$ & $30.374,634$ \\
\hline
\end{tabular}

Fonte: organização dos autores com base em dados de BRASIL (2017b) e IPARDES (2017). 
Para o setor da indústria também houve redução no número médio de empregos entre os anos, sendo que o desvio padrão apontou redução nas diferenças dos valores em relação à média. $\mathrm{O}$ setor de serviços apresentou uma média de empregos superior em 2016 com relação a 2012, com redução também no desvio padrão.

Para o ano de 2016 os efeitos da recessão auxiliariam na redução ou estagnação dos setores. Segundo IBGE (2017), o PIB brasileiro recuou em 3,6\% em 2016, com uma redução de 6,6\% na agropecuária, 3,8\% na indústria e 2,7\% no setor de serviços. A indústria é um dos setores mais dinâmicos da economia, por este motivo é influenciado de maneira mais expressiva pela recessão da economia. A queda no número médio de empregos fica evidente para a indústria, a partir dos dados desta pesquisa no Paraná.

\section{Análise univariada da autocorrelação espacial}

A fim de verificar a existência de padrões de associação espacial das variáveis selecionadas, foi calculada a estatística I de Moran global univariada, que testa a hipótese de aleatoriedade na distribuição espacial para cada uma das variáveis. A matriz de ponderação utilizada foi do tipo queen, ou rainha, que melhor representou a conexão entre os municípios. A Tabela 02 expõe a estatística I de Moran global univariada.

A estatística I de Moran apontou resultado positivo para todas as variáveis, ou seja, indica um padrão de similaridade dos dados. Isto quer dizer que municípios com alto IDEB estão rodeados por vizinhos que também apresentam alto índice, enquanto que municípios com baixo IDEB são rodeados por municípios igualmente com baixo índice. Isso se aplicada para todas as variáveis, já que todas apresentam resultado positivo, o que sugere uma relação entre as variáveis no mesmo sentido. A dinâmica apresentada pela estatística I de Moran univariada pode ser observada por meio do mapa de cluster, conforme Figura 1.

Tabela 02 - Estatística I de Moran global univariado

\begin{tabular}{ll|ll}
\hline Variável & I de Moran & Variável & I de Moran \\
\hline IDEB2007 & 0,293 & IDEB2011 & 0,3093 \\
QLAgropec2012 & 0,2139 & QLAgropec2016 & 0,2089 \\
QLComércio2012 & 0,196 & QLComércio2016 & 0,1628 \\
QLConstCivil2012 & 0,1173 & QLConstCivil2016 & 0,0972 \\
QLIndústria2012 & 0,2576 & QLIndústria2016 & 0,214 \\
QLServiços2012 & 0,1929 & QLServiços2016 & 0,1446 \\
\hline
\end{tabular}

Fonte: organização dos autores com base nos resultados extraídos do software GEODA.

Nota: o valor esperado da estatística apontou -0,0025 com 999 permutações e significância de 1\%. 
A partir da Figura 01 observa-se que, para o IDEB 2007, o padrão alto-alto forma um cluster de destaque que abrange municípios principalmente das Mesorregiões Oeste e Sudoeste. Isto demonstra que municípios com alto índice do IDEB em 2007 estavam rodeados por outros municípios também com alto índice do IDEB neste ano. Nota-se, igualmente, um cluster formado na Mesorregião Metropolitana de Curitiba e parte da Mesorregião Centro-Oriental de padrão baixo-baixo, ou seja, baixos índices do IDEB 2007 rodeados por municípios também com baixo IDEB. Para o ano de 2011 estes padrões foram mantidos.

Com relação ao QL agropecuário (Figura 01) constata-se que o destaque é para dois clusters de padrão baixo-baixo formados na Mesorregião Metropolitana de Curitiba e na junção das Mesorregiões Oeste e Sudoeste, demonstrando que especialmente municípios com baixos índices de especialização no setor agropecuário, possuem vizinhos com especialização neste setor também baixa. $O$ padrão é basicamente o mesmo apresentado para os anos de 2012 e 2016. Apesar dessas regiões apresentaram concentração de propriedades da agricultura familiar, o fato da especialização no setor ser baixa nestas regiões, pode estar associada à informalidade do trabalho familiar, visto que a RAIS compreende o trabalho formal.

Figura 01 - Mapa de cluster univariado local para as variáveis IDEB (2007 e 2011), QL agropecuário, QL comércio (2012 e 2016)

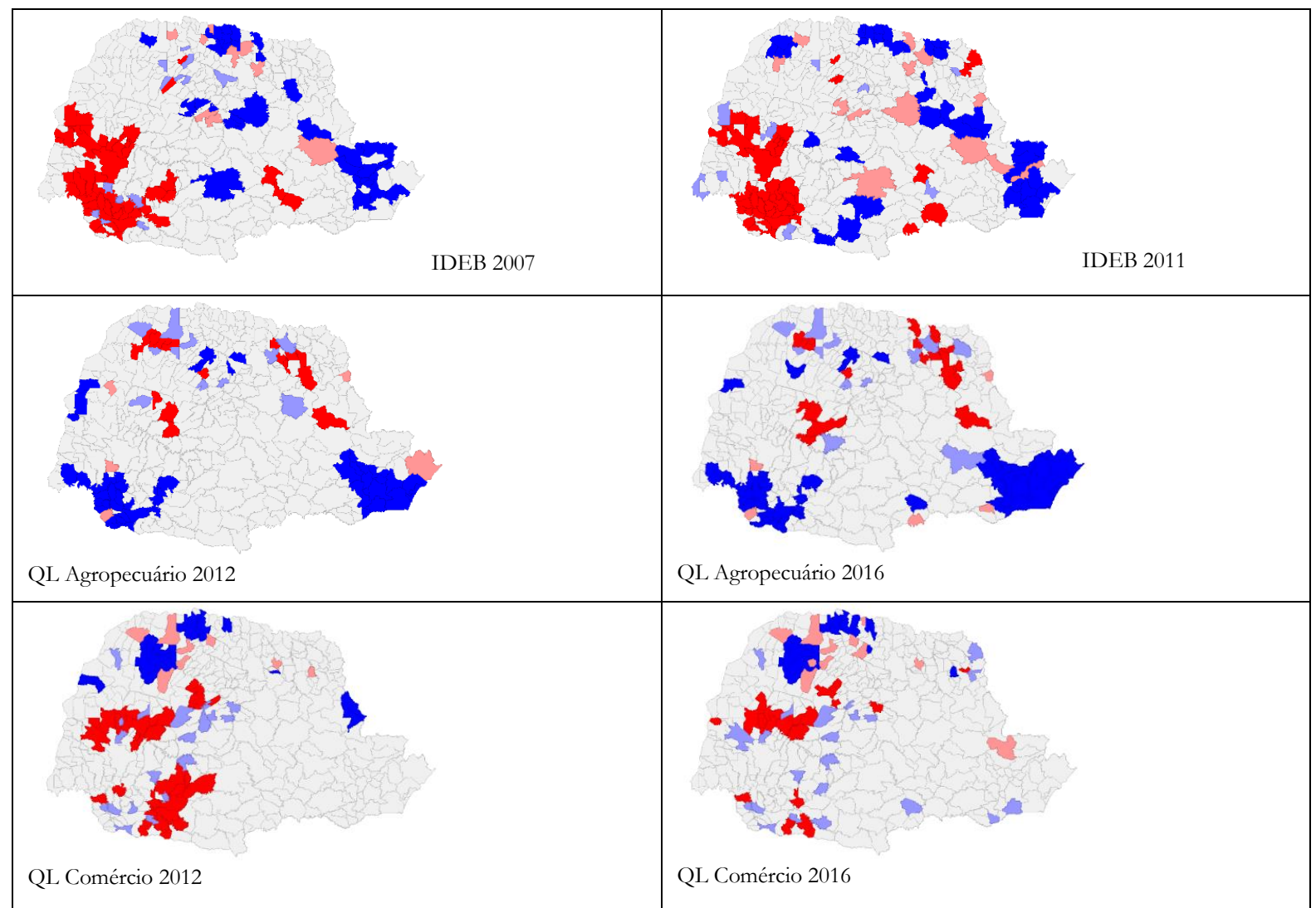

Fonte: organização dos autores com base nos resultados extraídos do software GEODA.

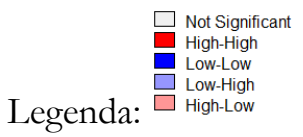


Para o QL do setor do comércio (Figura 01) o padrão espacial do ano de 2012 indica um cluster de padrão alto-alto entre as Mesorregiões Sudoeste e Centro-Sul e outro entre as Mesorregiões Oeste e Centro-Ocidental que se mantém para o ano de 2016, enquanto que o cluster entre Sudoeste e Centro-Sul deixa de existir. Há também um padrão de formação de aglomeração baixo-baixo na Mesorregião Noroeste para os dois anos. Conforme IBGE (2017) o setor do comércio é sensível a oscilações na economia, o que pode explicar essa distinção entre os anos é a recessão por qual a economia brasileira se encontrava em 2016.

$\mathrm{Na}$ Figura 02 é possível visualizar o QL da construção civil apresenta um cluster alto-alto mais expressivo na Mesorregião Metropolitana de Curitiba e parte da Mesorregião Centro-Oriental tanto para o ano de 2012 quanto para 2016. Uma possível explicação diz respeito à dinâmica da Mesorregião que polariza muitos empregos e é responsável por boa parte da migração intermunicipal.

Figura 02 - Mapa de cluster univariado local para as variáveis QL construção civil, QL indústria e QL serviços (2012 e 2016)

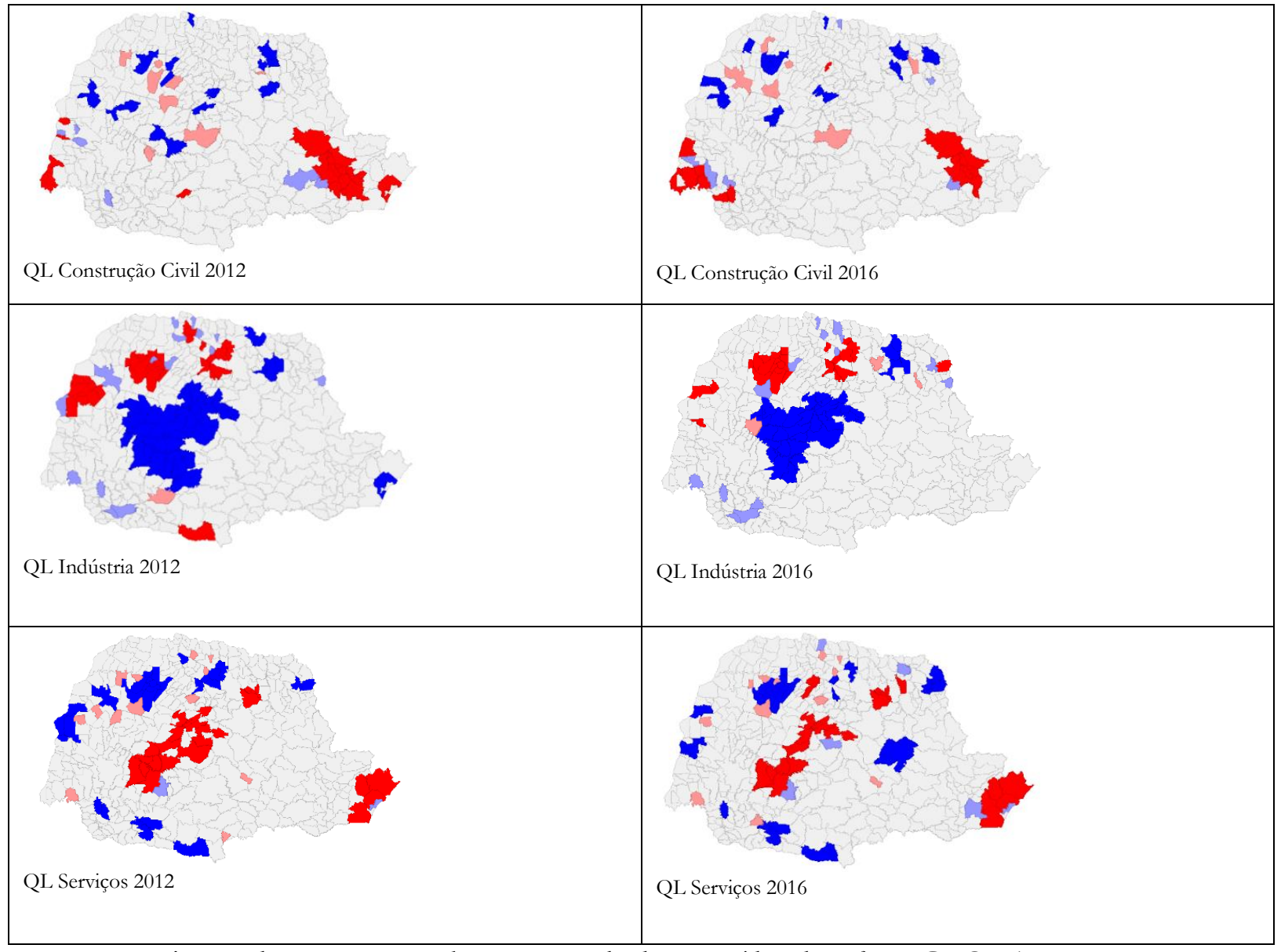

Fonte: organização dos autores com base nos resultados extraídos do software GEODA.

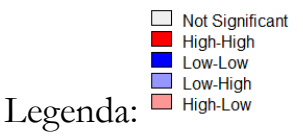


Quanto ao QL da indústria (Figura 02), destaca-se o cluster baixo-baixo formado principalmente por municípios da Mesorregião Centro-Sul Paranaense. Este padrão de similaridade acontece nos dois anos de estudo, sendo que em 2016 menos municípios fizeram parte da aglomeração. A mesorregião é uma das menos desenvolvidas do estado e a atividade predominante é a agropecuária.

Com relação ao QL de serviços (Figura 02), o padrão mais evidente é o alto-alto composto por municípios do leste da Mesorregião Oeste, parte das Mesorregiões Centro-Sul e Centro-Ocidental. Além deste, destaca-se também o mesmo padrão na Mesorregião Metropolitana de Curitiba tanto para 2012 quanto para 2016.

O principal realce da correlação univariada é que o padrão tende a manter-se do ano de 2012 para 2016, uma possível explicação é que o espaço de tempo pode não ser tão expressivo para que mudanças estruturais ocorram dentro dos setores e entre os municípios. Contudo, traz um panorama dessas relações entre os anos e reforça a robustez dos resultados.

Pode-se evidenciar também que o padrão expressado pelo I de Moran, sendo positivo para todas as variáveis, sugere a importância da espacialidade para estas variáveis, demonstrando haver influência da localização do município nestes aspectos. Este padrão pode sugerir que há um transbordamento da variável que ultrapassa os limites fronteiriços, que a qualidade do ensino pode ser transmitida entre municípios e que a especialização produtiva pode transbordar conhecimento que vai além dos limites político-administrativos.

Estes resultados vão de encontro ao objetivo proposto por esta pesquisa, que é de averiguar se há correlação espacial de municípios dos índices do IDEB e a especialização produtiva dos municípios vizinhos. Conforme apurado pelos resultados da análise univariada, a qualidade do ensino, medida pelo IDEB, tem uma autocorrelação espacial positiva, demonstrando que há uma tendência de aglomeração de padrões desta variável. O mesmo se observa com os padrões positivos apresentados pelo QL de todos os setores e para os dois anos analisados.

A seguir, será apresentada a análise bivariada combinando os efeitos das duas variáveis para cada um dos grandes setores produtivos.

\section{Análise bivariada local da autocorrelação espacial}

A estatística de autocorrelação bivariada, calculada por meio do I de Moran local, permite verificar se há alguma indicação de associação entre uma variável em determinado município e a média de outra variável nos municípios vizinhos. Neste caso, a intenção é averiguar se há algum tipo de autocorrelação entre o IDEB de determinado município com a média do QL de algum setor produtivo dos municípios vizinhos. A Tabela 03 exibe a estatística I de Moran local bivariada. 
Tabela 03 - Estatística I de Moran local bivariado

\begin{tabular}{ll|ll}
\hline Variável & I de Moran & Variável & I de Moran \\
\hline IDEB2007/QLAgropec2012 & $-0,1406$ & IDEB2011/QLAgropec2016 & $-0,112$ \\
IDEB2007/QLComércio2012 & 0,0835 & IDEB2011/QLComércio2016 & 0,0722 \\
IDEB2007/QLConstCivil2012 & 0,034 & IDEB2011/QLConstCivil2016 & 0,0248 \\
IDEB2007/QLIndústria2012 & 0,1167 & IDEB2011/QLIndústria2016 & 0,0931 \\
IDEB2007/QLServiços2012 & $-0,1041$ & IDEB2011/QLServiços2016 & $-0,0896$ \\
\hline
\end{tabular}

Fonte: organização dos autores com base nos resultados extraídos do software GEODA.

Nota: o valor esperado da estatística apontou -0,0025 com 999 permutações e significância de $1 \%$.

Nota-se que os valores da estatística I de Moran foram negativos para a associação de IDEB/QL agropecuário e de IDEB/QL serviços, tanto para 2012 quanto para 2016. Isso demonstra que a relação entre as duas variáveis é inversa, ou seja, se determinado município tem alto índice do IDEB, os municípios vizinhos possuem baixo QL no setor agropecuário ou no setor de serviços, ou seja, tem padrão de autocorrelação alto-baixo. Ou então, um município tem baixo IDEB e seus vizinhos possuem alto QL nos setores agropecuário ou de serviços, exprimindo um padrão baixo-alto.

As demais associações constataram valores positivos da estatística I de Moran o que indica que o padrão de associação é alto-alto ou baixo-baixo, ou seja, municípios com IDEB alto são rodeados por municípios com QL dos setores de comércio, construção civil e indústria também altos ou vice-versa. Observa-se, igualmente, que os valores expressam uma autocorrelação positiva de intensidade baixa, abaixo de 0,5 .

Ressalta-se que o setor agropecuário, conforme indicado por Pauli, Nakabashi e Sampaio (2012), é o que menos demanda mão de obra qualificada e que em geral a média de escolarização é menor que o ensino médio. Conforme destacado também pelos autores, o setor da indústria absorve mão de obra mais qualificada, indicando a relação encontrada nesta pesquisa, entre qualidade da educação e a especialização da indústria.

Já os valores encontrados para o setor de serviços se opõem ao apresentado por Pauli, Nakabashi e Sampaio (2012), dado que apresentaram uma relação negativa com o IDEB. Uma possível causa desta disparidade é que esse setor demanda grande parte da mão-de-obra com ensino superior, o que pode diferenciar da presente pesquisa por compreender especialmente o ensino básico. Outra possível explicação é que o setor de serviços envolve um sistema complexo de relações de trabalho, englobando trabalhadores com as diversas qualificações.

De acordo com Brasil (2017b), do ano de 2012 para o ano de 2016, elevou-se em 3,85\% o número de empregados no setor de serviços do estado do Paraná. A faixa de analfabetos tem uma expressão pequena do total, contudo apresentou aumento de 18,44\%, juntamente com a faixa referente ao ensino superior completo que teve aumento de 12,53\%. Em todas as outras faixas de escolaridade houve decréscimo, mais expressivo para o ensino médio completo. Esses dados indicam a diversidade da 
escolaridade nesse setor, podendo ser um indicativo de não haver uma relação direta entre a especialização do setor e o IDEB.

A Figura 03 representa o mapa de cluster bivariado local das associações entre as variáveis IDEB (2007 e 2011) e QL dos setores (2012 e 2016).

Com relação a associação de IDEB 2007/QL agropecuário 2012 pode-se notar um cluster formado nas Mesorregiões Oeste e Sudoeste Paranaense de padrão alto-baixo, ou seja, municípios com alto IDEB 2007 rodeados por municípios com QL agropecuário 2012 baixo. Outro destaque é o cluster baixo-baixo da Mesorregião Metropolitana de Curitiba, municípios com baixo IDEB 2007 rodeados por municípios com QL agropecuário também baixo. Este mesmo padrão é ainda maior para o ano de 2016 evidenciando que os dois clusters de destaque aumentaram.

Como na Mesorregião Metropolitana de Curitiba a produção agrícola é mais familiar e voltada para a produção de alimentos que atendam ao meio urbano, a capitalização é menor, levantando a questão apontada por Becker (1994) quanto à relação negativa entre a agricultura tradicional e a educação. Já para as Mesorregiões Sudoeste e Oeste Paranaense, apesar da predominância da agricultura familiar, é mais intensiva em capital, colaborando para uma associação maior com o nível de escolarização, apontado igualmente por Becker (1994).

Figura 03 - Mapa de cluster bivariado local para a correlação das variáveis IDEB (2007 e 2011), QL agropecuário, QL comércio, QL construção civil (2012 e 2016)

IDEB 2007/QL Agropecuário 2012

Fonte: organização dos autores com base nos resultados extraídos do software GEODA.

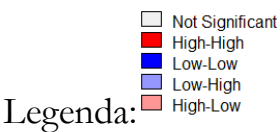


A associação de IDEB 2007/QL comércio 2012 (Figura 03) sinaliza um destaque para uma aglomeração alto-alto formado parte na Mesorregião Sudoeste e parte na Mesorregião Centro-Sul Paranaense. Este padrão não é verificado para o ano de 2016, sendo que a maioria das outras associações do estado permaneceram semelhantes a 2012. Como apontado por IBGE (2017) na análise univariada do setor do comércio, a recessão econômica de 2016 influenciou o setor que respondeu com a redução de empregos do setor e, portanto, a correlação pode ter se alterado no período.

No que atine à autocorrelação entre IDEB 2007 e QL do setor da construção civil 2012 (Figura 03) percebe-se, com maior proeminência, um cluster alto-alto formado entre as Mesorregiões Metropolitanas de Curitiba e do Centro-Oriental, que também se visualiza na associação entre o IDEB 2011 e o QL da construção civil 2016. Apesar do setor não ter uma ligação com níveis escolares mais altos, o resultado possivelmente diz respeito à influência da Mesorregião Metropolitana de Curitiba, que agrega muitos empregos e, por este motivo, a migração é mais constante.

A partir da Figura 04 nota-se que a associação de IDEB 2007/QL do setor da indústria exprime um padrão baixo-baixo entre as Mesorregiões Centro-Sul, Norte-Central e Centro-Ocidental. Essa dinâmica se mantém para a relação entre IDEB 2011 e QL da indústria 2016. Estas regiões compreendem alguns dos municípios menos desenvolvidos do estado, o que pode explicar a baixa industrialização associada a baixos índices do IDEB.

Já a relação entre IDEB 2007 e QL do setor de serviços (Figura 04), há formação de um pequeno cluster de padrão alto-alto na Mesorregião Noroeste, isto é, os municípios com alto IDEB possuem vizinhos também com alto QL no setor de serviços. O padrão é similar na relação entre o IDEB 2011 e o QL do setor de serviços 2016. Como já destacado, o setor de serviços é heterogêneo no que concerne à escolarização, portanto o padrão identificado pode estar relacionado ao desenvolvimento da região, que tende a se especializar em serviços.

A partir dos resultados encontrados por meio da AEDE, pode-se dizer que a educação tem correlação, mesmo que fraca, com o dinamismo e a especialização dos setores produtivos, alguns com mais influência do que outros, e é heterogêneo entre as regiões, dependendo das condições econômicas, sociais e do nível de desenvolvimento dos municípios. Assim como analisado por Schultz (1973), a educação da força de trabalho acaba gerando desenvolvimento produtivo, e segundo Becker (1994) isso é mais perceptível em economias menos desenvolvidas. 
Figura 04 - Mapa de cluster bivariado local para a correlação das variáveis IDEB (2007 e 2011) QL indústria e QL serviços (2012 e 2016)

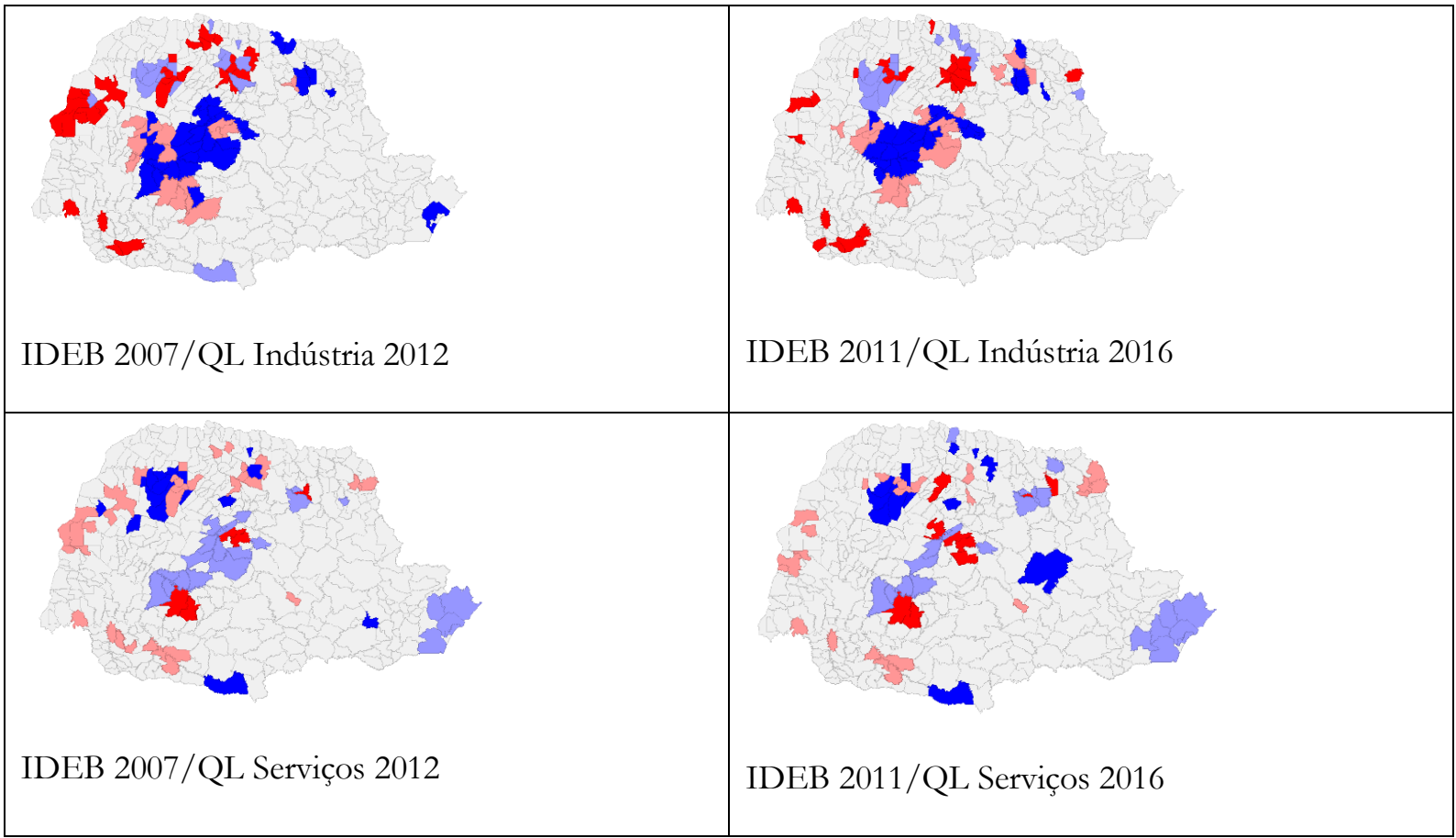

Fonte: organização dos autores com base nos resultados extraídos do software GEODA.

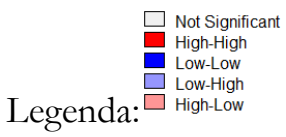

Becker (1994) também consente que a formação é de suma importância para o avanço da economia e põe como exemplo os Tigres Asiáticos, que passaram décadas investindo maciçamente em educação. É de se pensar que o Brasil, em toda a sua extensão, precise de décadas de investimentos ainda maiores, para alcançar os padrões destes países. Além disso, é necessária uma reforma social e educacional que por sua vez influencia significativamente no processo de aquisição de conhecimento, tanto formal como informal.

Conforme apontam Viana e Lima (2010) , a análise da influência da educação na economia deve levar em consideração a qualidade e não somente a quantidade. Por este motivo, a variável IDEB foi escolhida por representar um índice qualitativo aplicado à educação. Outrossim, Waltenberg (2006) se posiciona dizendo que muitos fatores influenciam a educação escolar e uma delas é todo o ambiente socioeconômico de vivência do estudante. Logo, os investimentos em educação precisam ser paralelamente amparados pelos investimentos em infraestrutura socioeconômica. 
Verificou-se que existe uma associação positiva, mesmo que fraca, entre alguns setores produtivos (comércio, construção civil e indústria) e o IDEB, o que quer dizer que existem concentrações espaciais com alto IDEB e alta especialização de algum dos setores em questão, ou mesmo que regiões com baixo IDEB tenham também baixa especialização. Estes resultados sugerem uma similaridade entre as variáveis e um transbordamento, tanto com relação a qualidade da educação, quanto com a especialização produtiva.

Este transbordamento é importante já que, não considerando as fronteiras entre os municípios, beneficia ao mesmo tempo muitos deles, criando aglomerações produtivas especializadas que conseguem inovar com mais facilidade, obter vantagens de custos de insumos e criar uma atmosfera de positividade com relação àquele setor, o que atrai ainda mais pessoas capacitadas. Este tipo de alcance observado pela expansão da produtividade gera um efeito positivo de crescimento e desenvolvimento, especialmente endógeno, na economia.

As aglomerações, ou clusters de padrão alto-alto, percebidos por meio dos resultados desta pesquisa atuam neste sentido de transbordamento positivo com relação tanto a qualidade da educação quanto da especialização produtiva.

A qualidade da educação é medular no desenvolvimento dos países. Como apontado por Schultz (1973) e Becker (1994), por meio da Teoria do Capital Humano, há um condicionante essencial para o sucesso das organizações, seja qual for o setor em que se insira o capital humano. Apesar de não ser a única maneira de agregar valor ao capital humano, a educação formal é uma das maneiras de formar a força de trabalho e gerar ganhos inovativos, de processos ou de produtos.

A formação da força de trabalho, como indicado por Batistela (2013), pode ser estimulada pelo governo, visto que o incentivo à escolarização produziria ganhos em todos os setores em que a mão-deobra especializada se inserisse. A formação técnica e as habilidades individuais também podem ser estimuladas via mudanças socioeconômicas, como indicado por Waltenberg (2006).

O desenvolvimento do capital humano é uma questão crucial para as economias, tendo em vista a importância para o crescimento da produtividade dos setores, além de características de inserção tecnológica e de gestão organizacional. Nesse contexto, a qualidade da educação formal é, por excelência, um campo importante a ser explorado. O crescimento da educação em termos quantitativos tem contribuído para a inserção dos indivíduos no mercado de trabalho, contudo, a exigência por especialização, especialmente nos setores mais tecnológicos, é um quesito alcançado por intermédio da educação de qualidade.

É evidente, que a contribuição governamental, por meio de políticas públicas de incentivo à educação, é essencial. Porém, os esforços em melhorar qualitativamente o ensino, com foco no ensino básico, é primordial para o desenvolvimento, não só dos setores produtivos, mas da nação como um todo. 
Desta maneira, é presumível que os governos, compreendendo essa importância, dirijam atenção multissetorial para este aspecto.

Este estudo indica possíveis caminhos para os policymakers brasileiros seguirem e transformar regiões com baixos índices do IDEB ou com pouca especialização, investindo corretamente, de acordo com o perfil produtivo ou com a necessidade educacional. É importante contar com análises que envolvam as dimensões econômica e educacional, para que seja possível planejar uma educação de qualidade, e que esta seja uma alavanca para o desenvolvimento da nação e para a qualidade de vida da população.

\section{Considerações finais}

Tendo em vista o contexto brasileiro de necessidade cada vez maior de qualidade de ensino, este estudo procurou verificar a existência de relação entre a qualidade do ensino, medida pelo IDEB e a especialização dos setores produtivos, medido pelo QL, nos municípios paranaenses, em comparação dos anos de 2012 e 2016. O intuito da pesquisa não foi esgotar o tema em questão, mas sim ser uma pesquisa inicial, para dar condições de aprofundar o tema.

O objetivo foi averiguar se a qualidade da educação afetou a especialização dos grandes setores produtivos e qual dos setores obteve mais influência. A proposta foi fazer uma análise espacial da correlação entre o índice do IDEB de determinado município e a especialização dos seus vizinhos, dentro de um cluster de similaridade proposto pela metodologia da AEDE.

Os resultados indicaram que tanto para 2012 quanto para 2016, a associação entre IDEB/QL agropecuário e IDEB/QL do setor de serviços possui uma relação negativa, ou seja, municípios com altos índices de IDEB possuem vizinhos com baixa especialização no setor agropecuário ou no setor de serviços, ou então municípios com baixos índices de IDEB estão rodeados de municípios com altos índices de especialização nestes dois setores.

Já o QL dos setores do comércio, indústria e construção civil possui relação positiva com IDEB, o que indica que eles registram padrões alto-alto ou baixo-baixo. Isto é, municípios com alto IDEB possuem vizinhos com alta especialização nestes três setores, ou vice-versa. O que a literatura sugere é que para o setor agropecuário a absorção de mão de obra mais qualificada é menor, portanto a relação negativa.

Um destaque importante é a formação de clusters, o que sugere que o fator espacial tem importância nos arranjos educacionais e produtivos, tanto na relação univariada como bivariada. Os transbordamentos intermunicipais são um dos indicativos dessas aglomerações de alto IDEB e alta 
especialização de determinado setor, ou mesmo daquelas aglomerações de baixo IDEB e baixa especialização.

Este estudo pode vir a ser um auxílio em novas pesquisas, em especial para que o estudo do tema futuramente seja uma base de planejamento dos investimentos em educação do estado do Paraná, assim como do planejamento produtivo e das relações entre os dois campos. Sugere-se que pesquisas futuras sejam realizadas, com outras variáveis, relacionando o ensino superior com a especialização produtiva ou mesmo analisando em detalhamento os setores.

\section{Referências}

ALMEIDA, E. Econometria espacial aplicada. Campinas: Alínea, 2012.

BASSI, C. CODES, A. ARAÚJO, H. E. O que muda com a reforma do ensino médio - conhecendo suas alterações, o debate e as lacunas. IPEA: nota técnica n ${ }^{\circ}$ 41, 2017.

BECKER, G. S. Human Capital Revisited: chapter II. In: Human Capital: A Theorical and Empirical Analysis with Special Reference to Education. 3rd edition, The University of Chicago Press: Chicago, p. 15-28, 1994.

BRASIL. Relação Anual de Informações Sociais (RAIS), 2017b. Disponível em: $<$ http://bi.mte.gov.br/bgcaged/login.php>. Acesso em 04 dez. 2017.

HADDAD, P. Medidas de localização e de especialização. In: HADDAD. P. \& FERREIRA, C. Economia Regional: teorias e métodos de análise. Fortaleza. BNB/ETENE, 1989. p. 225-245.

IBGE, 2017. Instituto Brasileiro de Geografia e Estatística. PIB recua 3,6\% em 2016 e fecha ano em R\$ 6,3 trilhões. Disponível em: <https://agenciadenoticias.ibge.gov.br/2013-agencia-denoticias/releases/9439-pib-recua-3-6-em-2016-e-fecha-ano-em-r-6-3-trilhoes.html>. Acesso em 11 abr. 2018.

Brasil em síntese: educação. 2018. Disponível em: $<$ https://brasilemsintese.ibge.gov.br/educacao.html>. Acesso em: 10 abr. 2018.

INEP. Instituto Nacional de Estudos e Pesquisas Educacionais Anísio Teixeira. Resumo técnico: Censo da educação superior 2014. - Brasília: Instituto Nacional de Estudos e Pesquisas Educacionais Anísio Teixeira, 2017. 55 p. 
INSTITUTO PARANAENSE DE DESENVOLVIMENTO ECONÔMICO E SOCIAL - IPARDES. Base de dados do IPARDES, 2017. Disponível em: < http://www.ipardes.gov.br/>. Acesso em: 05 dez. 2017.

MINISTÉRIO DA EDUCAÇÃO (MEC). Base Nacional Comum Curricular, 2019. Disponível em:

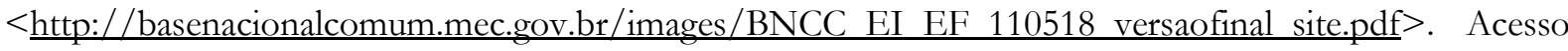
em: 18 set. 2019 .

PAULI, R. C. NAKABASHI, L. SAMPAIO, A. V. Mudança estrutural e mercado de trabalho no Brasil. Revista de Economia Política, vol. 32, no 3 (128), pp. 459-478, jul-set, 2012.

SCHULTZ, T. W. O valor econômico da educação. Rio de Janeiro. Editora: Zahar, 1973.

SOUZA, D. B. DUARTE, M. R. T. Planos de educação no Brasil: projeções do sistema nacional de educação e suas variantes subnacionais. Revista Educação Online, n. 15, jan./abr. p. 174-194, 2014.

SUZIGAN, W.; FURTADO, J.; GARCIA, R.; SAMPAIO, S. Sistemas Locais de Produção: mapeamento, tipologia e sugestões de políticas. Texto apresentado no XXXI Encontro Nacional de Economia - Porto Seguro, BA, dezembro de 2003.

VIANA, G. LIMA, J. F. Capital humano e crescimento econômico. Revista Interações, Campo Grande, v. 11, n. 2 p. 137-148, jul./dez. 2010.

WALTENBERG, F. D. Teorias econômicas de oferta de educação: evolução histórica, estado atual e perspectivas. Revista Educação e Pesquisa, São Paulo, v.32, n.1, p. 117-136, jan./abr. 2006.

Recebido em: setembro de 2019.

Aprovado em: outubro de 2019. 